\title{
Pengaruhi Kompensasi, Gaya Kepemimpinan Transformasional Dan Lingkungan Kerja Terhadap Kepuasaan Kerja
}

\author{
Yoshua Eko Adi Kustianto \\ Universitas Sarjanawiyata Tamansiswa \\ Email: yosuaekoadi@gmail.com \\ Diterima:April 2020;Dipublikasikan: Juli 2020
}

\begin{abstract}
ABSTRAK
Tujuan dari penelitian ini adalah untuk mendeskripsikan (1) pengaruh kompensasi terhadap kepuasaan kerja, (2) pengaruh gaya kepemimpinan transformasional terhadap kepuasaan kerja, (3) pengaruh lingkungan kerja terhadap kepuasaan kerja, (4) pengaruh kompensasi, gaya kepemimpinan transformasional, dan lingkungan kerja terhadap kepuasaan kerja, (5) variabel yang paling dominan memengaruhi kepuasaan kerja. Populasinya dalam Penelitian ini menggunakan semua pegawai tetap di CV Lintas Kreasi Yogyakarta yang berjumlah 50 orang sebagai populasinya. Teknik pengambilan sampel dilakukan secara non probability sampling dengan metode sampling jenuh. Metode pengumpulan data menggunakan kuesioner, sedangkan teknik analisis data menggunakan analisis regresi linear berganda yang didukung dengan uji $\mathrm{F}$ (F-test) dan uji T (T-test) dan uji asumsi klasik yang terdiri dari uji multikolenearitas, uji normalitas, uji heterokedastisitas, dan analisis regresi linear berganda. Hasil penelitian menunjukkan bahwa (1) Kompensasi berpengaruh positif signifikan terhadap Kepuasaan Kerja, (2) Gaya Kepemimpinan Trnasformasional berpengaruh positif signifikan terhadap Kepuasaan Kerja, (3) Lingkungan Kerja berpengaruh positif signifikan terhadap Kepuasaan Kerja, (4) Variabel Kompensasi, Gaya Kepemimpinan Transformasional, Lingkungan Kerja berpengaruh secara simultan dan positif signifikan terhadap Kepuasaan Kerja
\end{abstract}

Kata Kunci: kompensasi, gaya kepemimpinan transformasional, lingkungan kerja, kepuasaan kerja

\begin{abstract}
The purpose of this study is to describe (1) the effect of compensation on job satisfaction, (2) the influence of transformational leadership style on job satisfaction, (3) the influence of the work environment on job satisfaction, (4) the effect of compensation, transformational leadership style, and work environment on job satisfaction, (5) the most dominant variable influences job satisfaction. The population in this study uses all permanent employees in CV Lintas Kreasi Yogyakarta, totaling 50 people as the population. The sampling technique is done by nonprobability sampling with saturated sampling method. The data collection method uses a questionnaire, while the data analysis technique uses multiple linear regression analysis supported by the $\mathrm{F}$ test (F-test) and $\mathrm{T}$ test ( $\mathrm{T}$-test) and the classic assumption test consisting of multicollinearity test, normality test, heterokedasticity test, and multiple linear regression analysis. The results showed that (1) Compensation had a significant positive effect on Job Satisfaction, (2) Trnasformational Leadership Style had a significant positive effect on Job Satisfaction, (3) Work Environment had a significant positive effect on Job Satisfaction, (4) Compensation Variables, Transformational Leadership Style, Work Environment has a significant and simultaneous positive effect on Job Satisfaction
\end{abstract}

Keywords: compensation, transformational leadership style, work environment, job satisfaction

\section{PENDAHULUAN}

Dalam era modern seperti saat ini perkembangan dalam dunia bisnis semakin ketat dan semakin berkembang hal ini ditandai dengan adanya persaingan pengembangan produk yang semakin ketat, hal ini disertai dengan banyaknya target-target yang begitu tinggi yang diberikan atasan kepada staff dan karyawan dalam perusahaan, perkembangan industrialisasi dan inovasi teknologi yang tinggi dan pesat semakin membuat perusahaan menjadi lebih kompetitif dalam menghadapi persaingan yang semakin ketat dan sulit terutama dalam era globalisasi seperti saat ini(Lumentut \& Dotulong, 2015) . (Lumentut, 2015) Era globalisasi seperti saat ini menimbulkan persaingan yang ketat diantara perusahaan-perusahaan untuk mendapatkan mangsa pasar yang menjadi bidikannya, selain itu perusahaan juga dituntut untuk menggunakan teknologi yang modern mengikuti pasar yang ada, selain itu perusahaan juga harus 
memperhatikan pengelolaan dan pengkoordinasian sumber daya manusia dalam perusahaan yang lebih baik agar terjalinnya hubungan yang baik dan sinergi antara perusahaan dan karyawan yang ada di perusahaan. Sumber daya manusia (SDM) merupakan sebuah faktor utama yang sangat penting dalam suatu perusahaan disamping faktor lain seperti modal (Hariandja, 2007). Karyawan mempunyai berbagai macam harapan dari organisasi/ perusahaan, dan begitu juga sebaliknya (Kadarisman, 2011). Pada era globalisasi seperti saat ini pimpinan dalam sebuah perusahaan tidak hanya memperhatikan cara untuk memajukan perusahaan tetapi juga harus memperhatikan upaya untuk meningkatkan kepuasaan kerja dari karyawan dalam sebuah perusahaan agar karyawan mau bekerja lebih baik dan mengeluarkan kemampuan terbaik yang ia miliki dan mencapai kinerja yang maskimal agar dapat mencapai tujuan dari perusahaan (Putra \& Sariyathi, 2015). Oleh karena itu peneliti ingin melakukan analisis mengenai pengaruh kompensasi, gaya kepemimpinan transformasional dan lingkungan kerja terhadap kepuasaan kerja pada CV Lintas Kreasi Yogyakarta untuk mengetahui apakah ketiga variabel tersebut berpengaruh pada kepuasaan kerja karyawannya.

Faktor yang bisa menyebabkan kesenjangan dalam perusahaan ialah kurangnya pemahaman dari perusahaan dalam mengelola pemberian kompensasi. Kompensasi bisa menjadi sesuatu hal yang dapat menghambat kemajuan perusahaan apabila tidak dikontrol dengan baik. Kompensasi merupakan salah satu penunjang kinerja karyawan dalam bekerja. Pemberian kompensasi yang baik dan adil akan membantu individu dalam mengerjakan pekerjaanya dan dapat meningkatkan stimulus dalam bekerja. Kompensasi adalah segala sesuatu yang diterima para karyawan sebagai balas jasa untuk kerja mereka Handoko, 2008 dalam (Tambengi \& Kojo, 2016). Kompensasi adalah keseluruhan balas jasa yang diterima pegawai sebagai akibat dari pelaksanaan pekerjaan di organisasi dalam bentuk uang atau lainnya yang dapat berupa gaji, upah, bonus, insentif, dan tunjangan lainnya seperti tunjangan kesehatan,tunjangan hari raya, uang makan, uang cuti dan lain- lain Hariandja, (2007:244) dalam (Azies et al., 2014).

Dalam sebuah perusahaan, pengusaha harus cukup kompetitif dengan beberapa jenis kompensasi untuk memperkejakan, mempertahankan dan memberi imbalan terhadap kinerja di organisasi Atmajawati, (2007:5) dalam (Taufiqqurrokhman, 2015). Pemberian kompensasi yang benar, adil dan kuat akan berpengaruh pada meningkatnya kinerja karyawan, apabila pemberian kompensasi dirasa tidak adil maka akan menimbulkan kekecewaan pada karyawan, agar tidak meimbulkan kekecewaan maka kompensasi harus direncanakan agar karyawan terpuaskan, termotivasi dan merasa dihargai dalam bekerja, dan untuk mencapai tujuan - tujuan organisasi dan meningkatkan kinerja dalam perusahaan muljani, 2002 dalam (Astarina, 2018).

Hal ini selaras dengan penelitian yang dilakukan oleh (Humaeroh et al., 2015) Berdasarkan hasil penelitian ditemukan, bahwa kompensasi berpengaruh positif signifikan terhadap kepuasaan kerja karyawan dan penelitian yang dilakukan oleh (Muguongo et al., 2015) menunjukan adanya hubungan yang signifikan antara kepuasaan kerja dengan kompensasi. Hasil perusahaan yang meningkat tidak lepas dari kinerja karyawan yang ada di dalam perusahaan tersebut. Selain itu agar karyawan tetap bertahan dalam perusahaan diperlukan adanya kepemimpinan yang transformasional sehingga akan berdampak pada kepuasaan kerja karyawan di perusahaan (Daniati \& Mujiati, 2018). Menurut Munawaroh dalam (Italiani, 2018) mengemukakan bahwa kepemimpinan transformasional digambarkan sebagai gaya kepemimpinan yang mampu membangkitkan atau memotivasi karyawan, sehingga dapat berkembang dan mencapai kinerja pada tingkat yang tinggi, melebihi dari apa yang mereka perkirakan sebelumnya. Pengikut seorang pemimpin transformasional merasa adanya kepercayaan, kekaguman, kesetiaan, dan hormat terhadap pemimpin tersebut, dan mereka termotivasi untuk dapat melakukan lebih daripada yang awalnya diharapkan terhadap mereka (Anggraeni \& Santosa, 2019). Penelitian yang dilakukan oleh (Munir et al., 2012), terdapat hubungan yang positif dan signifikan antara kepemimpinan transformasional terhadap kepuasaan kerja karyawan pada staff pengajar sekolah di daerah Klang Valley, Malaysia. Penelitian (Ardianti et al., 2018) juga meneliti hubungan kompensasi dengan kepuaan kerja. Penelitian (Nursaid et al., 2020) juga meneliti hubungan antara kompensasi dengan kepuasan kerja. 
Selain itu faktor yang dapat mempengaruhi kepuasaan kerja karyawan ialah lingkungan kerja. lingkungan kerja di dalam suatu perusahaan juga tidak kalah penting untuk diperhatikan, Menurut Nitisemito, dalam (Nurhasanah, 2010) Lingkungan Kerja adalah segala sesuatu yang ada disekitar para pekerja dan yang dapat mempengaruhi dirinya dalam menjalankan tugastugas yang dibebankan. Misalnya kebersihan, musik, dan lain-lain. Lingkungan kerja dalam organisasi mempunyai pengaruh penting untuk kelancaran produksi dengan lingkungan yang sesuai, sehingga mampu memuaskan karyawan dalam melaksanakan kegiatan, tapi juga dapat berpengaruh terhadap peningkatan kinerja dan kepuasaan kerja karyawan (Setiawan \& Kartika Dewi, 2014). Lingkungan Kerja bisa meliputi 2 faktor yaitu lingkungan kerja fisik dan non fisik Pengertian lingkungan kerja fisik dan lingkungan kerja non fisik. Menurut Nitesemito dalam (Nurhasanah, 2010) adalah Lingkungan kerja fisik itu terdiri dari atas gedung kantor, perkakas dan tata ruang kantor serta kondisi-kondisi fisik dalam mana pegawai melaksanakan pekerjaannya. Sedangkan Lingkungan kerja non fisik bisa berupa (suasana kerja) diantaranya adalah hubungan kerja antar pegawai dan tata kerja (Nurhasanah, 2010). penelitian dari (Raziq \& Maulabakhsh, 2015) menunjukkan bahwa lingkungan kerja berpengaruh secara positif dan signifikan terhadap kepuasaan kerja pada karyawan lembaga pendidikan, karyawan bank, dan karyawan telekomunikasi industri dikota Quetta, Pakistan.

\section{Kompensasi}

\section{TINJAUAN PUSTAKA PENGEMBANGAN HIPOTESIS}

Menurut Hariandja, (2007:244) dalam (Azies et al., 2014) menjelaskan Kompensasi adalah keseluruhan balas jasa yang diterima pegawai sebagai akibat dari pelaksanaan pekerjaan di organisasi dalam bentuk uang atau lainnya yang dapat berupa gaji, upah, bonus, insentif, dan tunjangan lainnya seperti tunjangan kesehatan,tunjangan hari raya, uang makan, uang cuti dan lain- lain.

\section{Gaya Kepemimpinan Transformasional}

Menurut Munawaroh dalam (Italiani, 2018) mengemukakan bahwa kepemimpinan transformasional digambarkan sebagai gaya kepemimpinan yang mampu membangkitkan atau memotivasi karyawan, sehingga dapat berkembang dan mencapai kinerja pada tingkat yang tinggi, melebihi dari apa yang mereka perkirakan sebelumnya.

\section{Lingkungan Kerja}

Menurut Nitisemito, dalam (Nurhasanah, 2010) Lingkungan Kerja adalah segala sesuatu yang ada disekitar para pekerja dan yang dapat mempengaruhi dirinya dalam menjalankan tugas-tugas yang dibebankan.

\section{Kepuasaan Kerja}

Menurut Kreitner \& Kinicky dalam (Widyani \& Sugianingrat, 2015) mendefinisikan kepuasan kerja adalah sebuah respons emosional seseorang terhadap berbagai aspek pekerjaan, menurutnya seorang dapat relatif puas dengan suatu aspek dari pekerjaannya dan tidak puas dengan salah satu atau lebih aspek yang lainnya.

\section{Kompensasi Terhadap Kepuasaan Kerja}

Penelitian yang di lakukan oleh (Humaeroh et al., 2015) yang berjudul "Pengaruh Kompensasi Terhadap Kepuasaan Kerja Karyawan Dan Dampaknya Terhadap Motivasi Kerja (Studi pada Kryawan PT Krakatau Steel (Persero) Tbk.)", hasil dari penelitian ini menunjukkan bahwa Kompensasi finansial dan Kompensasi non finansial berpengaruh secara simultan dan parsial terhadap kepuasaan kerja dan motivasi kerja karyawan PT. Krakatau Steel (Persero) Tbk. H1: Kompensasi Berpengaruh Positif Terhadap Kepuasaan Kerja Pada Karyawan CV. Lintas Kreasi Yogyakarta 


\section{Gaya Kepemimpinan Transfomasrional Terhadap Kepuasaan Kerja}

Penelitian yang dilakukan oleh (Munir et al., 2012), yang berjudul "Pengaruh Gaya Kepemimpinan Transformasional terhadap Kepuasaan Kerja karyawan pada staff pengajar sekolah di daerah Klang Valley, Malaysia " dengan hasil penelitian kepemimpinan transformasional memberikan pengaruh yang positif dan signifikan terhadap kepuasaan kerja karyawan pada staff pengajar sekolah di daerah Klang Valley, Malaysia. Penelitian diatas dapat diturunkan menjadi hipotesis sebagai berikut:

H2: Gaya Kepemimpinan Transformasional Berpengaruh Positif Terhadap Kepuasaan Kerja Pada CV. Lintas Kreasi Yogyakarta

\section{Lingkungan Kerja Terhadap Kepuasaan Kerja}

Penelitian yang dilakukan (Raziq \& Maulabakhsh, 2015) yang berjudul Pengaruh Lingkungan Kerja Terhadap Kepuasaan Kerja Karyawan lembaga pendidikan, karyawan sektor perbankan dan telekomunikasi industri yang beroperasi di kota Quetta, Pakistan. menyatakan bahwa Lingkungan Kerja berpengaruh positif signifikan terhadap kepuasaan kerja karyawan lembaga pendidikan, karyawan sektor perbankan dan telekomunikasi industri yang beroperasi di kota Quetta, Pakistan.

H3: Lingkungan Kerja berpengaruh positif dan signifikan antara terhadap kepuasaan kerja karyawan.

\section{Kompensasi, Gaya Kepemimpinan Transformasional, Lingkungan Kerja terhadap Kepuasaan Kerja}

Penelitian dari (Daniati \& Mujiati, 2018) memperlihatkan hasil penelitian ini menunjukkan bahwa gaya kepemimpinan transformasional, kompensasi, dan lingkungan kerja berpengaruh positif terhadap kepuasaan kerja karyawan.

H4: Kompensasi, Gaya Kepemimpinan Transformasional dan Lingkungan Kerja berpengaruh positif dan signifikan antara terhadap kepuasaan kerja karyawan.

\section{METODE PENELITIAN}

Penelitian ini menggunakan metode kuantitatif dan metode pengumpulan data menggunakan kuesioner dengan 5 skala likert. Untuk variabel kompensasi menggunakan indikator dari Simamora (2004: 445) dalam penelitian (Abdussamad, 2014) sedangkan untuk variabel gaya kepemimpinan transformasional menggunakan indikator Robbins (2010:263) dalam penelitian (Awaludin, 2016) sedangkan untuk variabel lingkungan kerja menggunakan indikator Simamora (2004:46) dalam penelitian (Wuwungan et al., 2017) dan untuk variabel kepuasaan kerja menggunakan indikator dari spector Yuwono (2005:69) dalam penelitian (Prastyo et al., 2016). Populasi penelitian adalah seluruh karyawan CV Lintas Kreasi Yogyakarta yang berjumlah 50 responden, dengan teknik pengambilan sampel non probability sampling, dengan metode sampling jenuh yang berarti bahwa jika responden kurang dari 100 maka semua responden yang telah mengisi kuisioner digunakan semua (Arikunto, 2019). Sampel yang digunakan adalah sampling jenuh.

\section{Devinisi Operasional Kompensasi}

Menurut Hariandja, (2007:244) dalam (Azies et al., 2014) menjelaskan Kompensasi adalah keseluruhan balas jasa yang diterima pegawai sebagai akibat dari pelaksanaan pekerjaan di organisasi dalam bentuk uang atau lainnya yang dapat berupa gaji, upah, bonus, insentif, dan tunjangan lainnya seperti tunjangan kesehatan,tunjangan hari raya, uang makan, uang cuti dan lain- lain.

Variabel Kompensasi (KOM) Menurut Simamora (2004:445) dalam (Abdussamad, 2014) memiliki indikator sebagai berikut: Upah dan Gaji , Insentif, Tunjangan , Fasilitas

\section{Devinisi Operasional Gaya Kepemimpinan Transfromasional}

Menurut Munawaroh dalam (Italiani, 2018) mengemukakan bahwa kepemimpinan transformasional digambarkan sebagai gaya kepemimpinan yang mampu membangkitkan atau 
memotivasi karyawan, sehingga dapat berkembang dan mencapai kinerja pada tingkat yang tinggi, melebihi dari apa yang mereka perkirakan sebelumnya.

Variabel Gaya Kepemimpinan Transformasional (GKT) Menurut Robbins (2010:263) dalam (Awaludin, 2016) memiliki indikator sebagai berikut: Kharisma, Inspirasi, Rangsangan Intelektual , Pertimbangan yang di individualkan

\section{Devinisi Operasional Lingkungan Kerja}

Menurut Nitisemito, dalam (Nurhasanah, 2010) Lingkungan Kerja adalah segala sesuatu yang ada disekitar para pekerja dan yang dapat mempengaruhi dirinya dalam menjalankan tugas-tugas yang dibebankan.

Variabel Lingkungan Kerja (LK) Menurut Sedarmayanti (2004:46) dalam (Wuwungan et al., 2017) memiliki indikator sebagai berikut: Penerangan di tempat kerja, Temperatur di tempat kerja, Sirkulasi Udara di tempat kerja, Kebisingan di tempat kerja, Bau yang tidak sedap ditempat kerja, Musik ditempat kerja, Keamanan ditempat kerja

\section{Devinisi Operasional Kepuasaan Kerja}

Menurut Kreitner \& Kinicky dalam (Widyani \& Sugianingrat, 2015) mendefinisikan kepuasan kerja adalah sebuah respons emosional seseorang terhadap berbagai aspek pekerjaan, menurutnya seorang dapat relatif puas dengan suatu aspek dari pekerjaannya dan tidak puas dengan salah satu atau lebih aspek yang lainnya.

Variabel Kepuasaan Kerja (KK) Menurut Yuwono (2005: 69) dalam (Prastyo et al., 2016) memiliki indikator sebagai berikut: Promosi, Supervisi , Benefit, Coworkers, Nature of work

\section{HASIL DAN PEMBAHASAN}

Tabel 1. Uji Validitas dan Reliabilitas

\begin{tabular}{|c|c|c|c|c|c|c|c|}
\hline \multicolumn{2}{|c|}{$\begin{array}{l}\text { Kompensasi } \\
(\mathrm{KOM})\end{array}$} & \multicolumn{2}{|c|}{$\begin{array}{c}\text { Gaya } \\
\text { Kepemimpinan } \\
\text { Transformasional } \\
\text { (GKT) } \\
\end{array}$} & \multicolumn{2}{|c|}{$\begin{array}{l}\text { Lingkungan Kerja } \\
\text { (LK) }\end{array}$} & \multicolumn{2}{|c|}{$\begin{array}{c}\text { Kepuasaan Kerja } \\
(\mathrm{KK})\end{array}$} \\
\hline KOM1 & 0,645 & GKT1 & 0,690 & LK1 & 0,681 & KK1 & 0,692 \\
\hline KOM2 & 0,528 & GKT2 & 0,808 & LK2 & 0,649 & KK2 & 0,737 \\
\hline KOM3 & 0,559 & GKT3 & 0,655 & LK3 & 0,472 & KK3 & 0,597 \\
\hline KOM4 & 0,657 & GKT4 & 0,655 & LK4 & 0,713 & KK4 & 0,709 \\
\hline KOM5 & 0,573 & GKT5 & 0,634 & LK5 & 0,495 & KK5 & 0,617 \\
\hline KOM6 & 0,557 & GKT6 & 0,571 & LK6 & 0,506 & KK6 & 0,670 \\
\hline \multirow[t]{2}{*}{ KOM7 } & 0,654 & GKT7 & 0,553 & LK7 & 0,646 & KK7 & 0,666 \\
\hline & & GKT8 & 0,550 & & & & \\
\hline \multicolumn{8}{|c|}{ Cronbach's Alpha Based on Standardized Items } \\
\hline \multicolumn{2}{|c|}{0,691} & \multicolumn{2}{|c|}{0,778} & \multicolumn{2}{|c|}{0,700} & \multicolumn{2}{|c|}{0,796} \\
\hline
\end{tabular}

Hasil uji validitas (Tabel 1) menunjukkan nilai corrected item-total correlation $>$ dari $r$ table $(0,2353)$ atau valid. Pengujian menghasilkan $r$ hitung kompensasi $(0,528$ s.d. 0,657$)$, gaya kepemimpinan transformasional $(0,550$ s.d. 0,808$)$, lingkungan kerja $(0,472$ s.d. 0,713$)$, dan kepuasaan kerja $(0,597$ s.d. 0,737) $>0,2353$. Cronbach's Alpha Stand. kompensasi $(0,691)$, gaya kepemimpinan transformasional $(0,778)$, lingkungan kerja $(0,700)$, dan kepuasaan kerja $(0,796)$ $>0,60$ atau instrumen reliabel.

Sebagian besar responden pada CV Lintas Kreasi Yogyakarta adalah laki - laki (88\%) (tabel 2). Mayoritas para responden berusia 35-49 tahun (42\%) dan berdasarkan pendidikan terakhir paling banyak adalah SMA (44\%). 
Tabel 2. Karakteristik Responden

\begin{tabular}{ccc}
\hline Kategori & Frekuensi & Presentase \\
\hline Usia & & \\
\hline 17-24 tahun & 6 & $12 \%$ \\
24-34 tahun & 15 & $30 \%$ \\
35-49 tahun & 21 & $42 \%$ \\
50-64 tahun & 8 & $16 \%$ \\
\hline Jenis Kelamin & & \\
\hline Laki-Laki & 44 & $12 \%$ \\
Perempuan & 6 & \\
Pendidikan Terakhir & & $40 \%$ \\
SMP & 20 & $44 \%$ \\
SMA & 22 & $16 \%$ \\
SARJANA & 8 &
\end{tabular}

Tabel 3 Asumsi Klaik

\begin{tabular}{|c|c|c|c|c|c|c|}
\hline Mdl. & \multicolumn{2}{|c|}{ Variabel } & \multirow{2}{*}{$\begin{array}{c}\text { Normalitas } \\
\text { Sig. }\end{array}$} & \multirow{2}{*}{$\begin{array}{c}\text { Heteroskedastisitas } \\
\text { Sig. }\end{array}$} & \multicolumn{2}{|c|}{ Multikolonieritas } \\
\hline & $\begin{array}{c}\text { Beba } \\
\text { s }\end{array}$ & $\begin{array}{c}\text { Terika } \\
\mathrm{t}\end{array}$ & & & Tol. & VIF \\
\hline \multirow{3}{*}{1} & Kom & & & 0,894 & 0,955 & 1,048 \\
\hline & Gkt & $\mathrm{Kk}$ & 0,869 & 0,829 & 0,941 & 1,063 \\
\hline & Lk & & & 0,859 & 0.937 & 1.067 \\
\hline
\end{tabular}

Tabel 3 menunjukkan model regresi tidak mengalami multikolonieritas (tolerance $>0,10$ dan VIF < 10), tidak mengalami heteroskedastisitas dan data terdistribusi normal (KolmogorovSmirnov test memiliki asymp sig>0,05).

Tabel 5 Pengujian Hipotesis

\begin{tabular}{ccccccc}
\hline Hip. & \multicolumn{2}{c}{ Variabel } & \multicolumn{2}{c}{ Stand. Coeff. } & Sig. & $\begin{array}{c}\text { Koef. Detr. } \\
\text { Adj. } R \text { Sq }\end{array}$ \\
& Bebas & Terikat & Beta & $T$ & & \\
\hline H1 & Kom & & 0,264 & 1,860 & 0,069 & \\
H2 & Gkt & \multirow{2}{*}{ Kk } & 0,284 & 2,214 & 0,032 & 0,293 \\
H3 & Lk & & 0,333 & 2,205 & 0,032 & \\
\hline
\end{tabular}

Hasil pengujian hipotesis menunjukkan bahwa $\mathrm{H} 1$ diterima karena nilai sig. 0,069/2 < 0,05. H2 diterima dengan nilai sig. 0,032/2 <0,05. H3 diterima dengan nilai sig. 0,032/2 < 0,05. kompensasi, gaya kepemimpinan transformasional dan lingkungan kerja terhadap kepuasaan kerja memiliki adjusted $R$ square sebesar $29,3 \%$, sisanya 70,7\% dipengaruhi faktor lain, serta pada tabel ini dijelaskan pengaruh variabel paling dominan yaitu gaya kepemimpinan transformasional Uji F.

Tabel 4 Hasil Uji F

\begin{tabular}{|c|c|c|c|c|c|c|}
\hline Model & & Sum of Squares & $\mathrm{df}$ & Mean Square & $\mathrm{F}$ & Sig. \\
\hline \multirow{3}{*}{1} & Regression & 465,856 & 3 & 155,285 & 6,358 &, $001^{\mathrm{a}}$ \\
\hline & Residual & 1123,524 & 46 & 24,424 & & \\
\hline & Total & 1589,380 & 49 & & & \\
\hline
\end{tabular}


Berdasarkan tabel diatas dapat diketahui nilai $\mathrm{F}$ hitung $>\mathrm{F}$ tabel yaitu 6,358 > 2,80, maka dapat dikatan uji $\mathrm{F}$ variabel kompensasi, gaya kepemimpinan transformasional, lingkungan kerja secara simultan berpengaruh terhadap kepuasaan kerja. Hasil ini sesuai dengan hasil penelitian yang dilakukan oleh Daniati,Mujiati 2018 bahwa Kompensasi, Gaya Kepemimpinan Transformasional, dan Lingkungan Kerja secara bersama-sama berpengaruh secara smilutan dan signifikan terhadap kepuasaan kerja.

\section{Pembahasan}

Berdasarkan hasil dari penelitian yang telah dilakukan, menunjukan bahwa kompensasi memiliki pengaruh signifikan positif terhadap kepuasaan kerja karyawan CV Lintas Kreasi Yogyakarta penelitian ini didukung dengan hasil penelitian yang dilakukan oleh Sabeli Humaeroh, Heru dan Arik (2015) bahwa secara parsial variabel kompensasi (X1) memiliki pengaruh positif signifikan terhadap Kepuasaan Kerja PT. Krakatau Steel (persero) Tbk, (Humaeroh et al., 2015). Hasil penelitian kedua menunjukan bahwa gaya kepemimpinan transformasional memiliki pengaruh signifikan positif terhadap kepuasaan kerja karyawan CV Lintas Kreasi Yogyakarta, penelitian ini didukung yang dilakukan oleh Munir (2012) menjelaskan bahwa terdapat hubungan yang signifikan positif antara variabel gaya kepemimpinan transformasional dengan kepuasaan kerja karyawan pada staff pengajar sekolah di daerah Klang Valley Malaysia (Munir et al., 2012). Hasil penelitian yang ketiga, menunjukan bahwa lingkungan kerja memiliki pengaruh signifikan positif terhadap kepuasaan kerja karyawan CV Lintas Kreasi Yogyakarta, penelitian ini didukung oleh Raheela Maulabaksh (2015) pada karyawan lembaga pendidikan, karyawan sektor perbankan dan telekomunikasi industri yang beroperasi di kota Quetta, Pakistan pada hasil penelitiannya menunjukkan bahwa terdapat pengaruh yang positif dan signifikan lingkungan kerja terhadap kepuasaan kerja (Raziq \& Maulabakhsh, 2015). Hasil penelitian keempat menunjukan bahwa Kompensasi, Gaya Kepemimpinan Transformasional dan Lingkungan Kerja secara simultan memiliki pengaruh signifikan positif terhadap Kepuasaan Kerja Karyawan. penelitian ini juga menunjukan bahwa Variabel independen yang paling besar pengaruhnya pada penelitian yang dilakukan di CV Lintas Kreasi Yogyakarta adalah variabel gaya kepemimpinan transformasional yaitu sebesar 0,283

\section{KESIMPULAN, SARAN DAN IMPLIKASI}

Kompensasi memiliki pengaruh signifikan positif terhadap kepuasaan kerja karyawan CV Lintas Kreasi Yogyakarta. Hal ini didasarkan pada hasil regresi, t tabel kompensasi sebesar 1,860> 1,672 dan signifikansi 0,069/2 lebih kecil dari 0,05. Gaya Kepemimpinan Transformasional memiliki pengaruh signifikan positif terhadap Kepuasaan Kerja karyawan CV Lintas Kreasi Yogyakarta. Hal ini didasarkan pada hasil regresi, t tabel keterampilan kerja 2,214 $>1,672$ dan signifikansi sebesar 0,032/2 lebih kecil dari 0,05. Lingkungan Kerja memiliki pengaruh signifikan positif terhadap produktivitas kerja karyawan CV Lintas Kreasi Yogyakarta. Hal ini didasarkan pada hasil regresi, t tabel lingkungan kerja sebesar 2,205 > 1,672 dan sebesar 0,032/2 lebih kecil atau dibawah 0,05, Hal ini berarti jika kondisi lingkungan kerja nyaman, kondusif, dan menyenangkan akan mempengaruhi suasana kerja karyawan dan tentunya berpengaruh dan meningkatkan kepuasaan kerja Karyawan. Kompensasi, Gaya Kepemimpinan Transformasional dan Lingkungan Kerja secara simultan memiliki pengaruh signifikan positif terhadap Kepuasaan Kerja Karyawan. Hal ini didasarkan bahwa nilai f hitung $6.358>2,80 \mathrm{f}$ tabel dan nilai sig $0,001<0,05$, Artinya jika ada peningkatan kualitas dari ketiga variabel (kompensasi, gaya kepemimpinan transformasional dan lingkungan kerja) akan berpengaruh pada Variabel Kepuasaan Kerja Karyawan CV Lintas Kreasi Yogyakarta.

Berdasarkan nilai dari beberapa item indikator pada variabel gaya kepemimpinan transformasional, gaya kepemimpinan transformasional memiliki jumlah jawaban netral tertinggi. Hal tersebut mencerminkan bahwa responden belum sepenuhnya nyaman terhadap kondisi pimpinan yang ada diperusahaan. Oleh karena itu, CV Lintas Kreasi Yogyakarta disarankan untuk lebih memperhatikan dan memperbaiki Sistem kepemimpinan yang ada diperusahaan, terutama pada indikator pertimbangan yang di individualkan, kemudian pada 
indikator Kharisma pimpinan harus bisa menanamkan rasa bangga bekerja di perusahaan dan pada indikator Inspirasi bisa dilakukan dengan memberikan solusi dan pemecahan masalah bagi karyawan dan pimpinan diharapkan memberikan motivasi pada karyawannya.

Saran bagi peneliti selanjutnya yaitu, sebaiknya bisa mengganti variabel yang sudah dipakai, agar hasil dari penelitian bisa lebih baik tetapi harus melihat apakah hasilnya juga akan memiliki pengaruh signifikan positif bagi kepuasaan kerja karyawan CV Lintas Kreasi Yogyakarta selain itu peneliti bisa menambahkan variable lainnya selain variabel yang telah digunakan dalam penelitian ini untuk lebih mengetahui mengenai hubungan variabel independen terhadap variabel dependen.

\section{DAFTAR PUSTAKA}

Abdussamad, Z. (2014). Pengaruh Kompensasi Terhadap Produktivitas Kerja Karyawanpada Pt Asuransi Jiwasraya Gorontalo. Jurnal Manajemen, XVIII(03), 456-466.

Anggraeni, Y., \& Santosa, E. C. (2019). PENGARUH KEPEMIMPINAN TRANSFORMASIONAL TERHADAP KEPUASAN KERJA KARYAWAN. 6, 1-8.

Ardianti, F. E., Qomariah, N., \& Wibowo, Y. G. (2018). PENGARUH MOTIVASI KERJA, KOMPENSASI DAN LINGKUNGAN KERJA TERHADAP KEPUASAN KERJA KARYAWAN (Studi Kasus Pada PT. Sumber Alam Santoso Pratama Karangsari Banyuwangi) EFFECT. Jurnal Sains Manajemen \& Bisnis Indonesia, 8(1), 13-31.

Astarina, I. (2018). Pengaruh Motivasi Dan Kompensasi Terhadap Kinerja Karyawan Pada Pt. Alfa Scorpii Pematang Reba. Jurnal Manajemen dan Bisnis, 7(4), 1-9. https://doi.org/10.34006/jmb.v7i4.2

Awaludin, A. (2016). HUBUNGAN GAYA KEPEMIMPINAN TRANSFORMASIONAL DENGAN KINERJA KARYAWAN PADA PT. YUNI INTERNATIONAL. Journal Ekobis Universitas Pakuan Bogor, 1, 1-10.

Azies, B., Made, N., Gunawati, D., Manajemen, P. S., Ekonomi, F., \& Yapis, U. (2014). F utur E. 11, 23-40.

Daniati, N. L. H., \& Mujiati, N. W. (2018). PENGARUH GAYA KEPEMIMPINAN TRANSFORMASIONAL, KOMPENSASI, DAN LINGKUNGAN KERJA TERHADAP KEPUASAN KERJA KARYAWAN PADA LPD KEROBOKAN. E-Jurnal Manajemen Unud, 7(7), 3856-3885.

Hariandja, M. T. E. (2007). Manajemen Sumber Daya Manusia: Pengadaan, Pengembangan, Pengkompensasian, dan Peningkatan Produktivitas Pegawai.

Humaeroh, Susilo, H., \& Prasetya, A. (2015). Pengaruh Kompensasi terhadap Kepuasan Kerja Karyawan dan Dampaknya terhadap Motivasi Kerja ( Studi pada Karyawan PT Krakatau Steel ( Persero ) Tbk .). Jurnal Administrasi Bisnis (JAB), 27(2), 1-8.

Italiani, F. A. (2018). Pengaruh Gaya Kepemimpinan Transformasional Dan Transaksional Terhadap Kinerja Pegawai Departemen SDM PT. SEMEN GRESIK (Persero) Tbk. BISMA (Bisnis dan Manajemen), 6(1), 11. https://doi.org/10.26740/bisma.v6n1.p11-18

Kadarisman, M. (2011). Pengertian dan Filosofi Manajemen Kompensasi. Manajemen Sumber Daya Manusia, 1-53.

Lumentut, M. D. ., \& Dotulong, L. O. . (2015). Pengaruh Motivasi, Disiplin, dan Lingkungan Kerja Terhadap Kepuasan Kerja Karyawan Pada PT. Bank SULUT Cabang Airmadidi. Jurnal EMBA, ISSN: 2303-1174, 3(1), 74-85.

Muguongo, M. M., Muguna, A. T., \& Muriithi, D. K. (2015). Effects of Compensation on Job Satisfaction Among Secondary School Teachers in Maara Sub - County of Tharaka Nithi County, Kenya. 3(6), 47-59. https://doi.org/10.11648/j.jhrm.20150306.11

Munir, R. I. S., Rahman, R. A., Malik, A. M. A., \& Ma'amor, H. (2012). Relationship between Transformational Leadership and Employees' Job Satisfaction among the Academic Staff. Procedia - Social and Behavioral Sciences, 65(ICIBSoS), 885-890. https://doi.org/10.1016/j.sbspro.2012.11.215

Nurhasanah, A. (2010). Kerja Karyawan Pada Bank Indonesia Cabang Samarinda. 6(1), 13491356. 
Nursaid, N., Qomariah, N., Sanosra, A., Satoto, E. B., \& Utomo, A. W. (2020). Improvement of Job Satisfaction Based on Work Motivation, Work Environment, Competence and Compensation for Hospital Employees. Indonesian Journal Of Law and Economic Review, l(1).

Prastyo, E., Hasiholan, L., Management, M. W.-J. of, \& 2016, U. (2016). Pengaruh Motivasi, Kepuasan, dan Lingkungan Kerja Terhadap Kinerja Karyawan Honorer Dinas Bina Marga Pengairan dan ESDM Kabupaten Jepara. Jurnal.Unpand.Ac.Id, 02(02).

Putra, I., \& Sariyathi, N. (2015). Pengaruh Gaya Kepemimpinan Transformasional, Lingkungan Kerja Dan Kompensasi Terhadap Kepuasan Kerja Karyawan Langgeng Laundry Di Kuta, Badung. E-Jurnal Manajemen Universitas Udayana, 4(5), 1345-1364.

Raziq, A., \& Maulabakhsh, R. (2015). Impact of Working Environment on Job Satisfaction. Procedia Economics and Finance, 23(October 2014), 717-725. https://doi.org/10.1016/s2212-5671(15)00524-9

Setiawan, F., \& Kartika Dewi, A. (2014). Pengaruh Kompensasi dan Lingkungan Kerja Terhadap Kinerja Karyawan Pada CV. Berkat Anugrah. E-Jurnal Manajemen Universitas Udayana, 3(5), 1471-1490.

Tambengi, Kevin F.S., Kojo, Christoffel, Rumokoy, F. S. (2016). Pengaruh Kompensasi, Beban Kerja, Dan Pengembangan Karir Terhadap Kepuasan Kerja Karyawan Pada Pt. Telekomunikasi Indonesia Tbk. Witel Sulut. Emba, 4(4), 1088-1097.

Taufiqqurrokhman, I. (2015). PENGARUH LINGKUNGAN KERJA DAN KOMPENSASI TERHADAP TURNOVER INTENTION PADA SWALAYAN BENTAR MOJOKERTO. Journal Ekobis Universitas Muhammadiyah Malang, 2(1), 1689-1699. https://doi.org/10.1017/CBO9781107415324.004

Widyani, A., \& Sugianingrat, I. (2015). Effect of multiple role conflict on job satisfaction with the mediation role of stress. International Journal of Economics, Commerce and Management, 3(5), 868-870.

Wuwungan, R., Taroreh, R., \& Uhing, Y. (2017). Pengaruh Lingkungan Kerja Dan Motivasi Kerja Terhadap Kepuasan Kerja Karyawan Cinemaxx Lippo Plaza Manado. Jurnal Riset Ekonomi, Manajemen, Bisnis dan Akuntansi, 5(2), 298-307.

Abdussamad, Z. (2014). Pengaruh Kompensasi Terhadap Produktivitas Kerja Karyawanpada Pt Asuransi Jiwasraya Gorontalo. Jurnal Manajemen, XVIII(03), 456-466.

Anggraeni, Y., \& Santosa, E. C. (2019). PENGARUH KEPEMIMPINAN TRANSFORMASIONAL TERHADAP KEPUASAN KERJA KARYAWAN. 6, 1-8.

Ardianti, F. E., Qomariah, N., \& Wibowo, Y. G. (2018). PENGARUH MOTIVASI KERJA, KOMPENSASI DAN LINGKUNGAN KERJA TERHADAP KEPUASAN KERJA KARYAWAN (Studi Kasus Pada PT. Sumber Alam Santoso Pratama Karangsari Banyuwangi) EFFECT. Jurnal Sains Manajemen \& Bisnis Indonesia, 8(1), 13-31.

Astarina, I. (2018). Pengaruh Motivasi Dan Kompensasi Terhadap Kinerja Karyawan Pada Pt. Alfa Scorpii Pematang Reba. Jurnal Manajemen dan Bisnis, 7(4), 1-9. https://doi.org/10.34006/jmb.v7i4.2

Awaludin, A. (2016). HUBUNGAN GAYA KEPEMIMPINAN TRANSFORMASIONAL DENGAN KINERJA KARYAWAN PADA PT. YUNI INTERNATIONAL. Journal Ekobis Universitas Pakuan Bogor, 1, 1-10.

Azies, B., Made, N., Gunawati, D., Manajemen, P. S., Ekonomi, F., \& Yapis, U. (2014). F utur E. 11, 23-40.

Daniati, N. L. H., \& Mujiati, N. W. (2018). PENGARUH GAYA KEPEMIMPINAN TRANSFORMASIONAL, KOMPENSASI, DAN LINGKUNGAN KERJA TERHADAP KEPUASAN KERJA KARYAWAN PADA LPD KEROBOKAN. E-Jurnal Manajemen Unud, 7(7), 3856-3885.

Hariandja, M. T. E. (2007). Manajemen Sumber Daya Manusia: Pengadaan, Pengembangan, Pengkompensasian, dan Peningkatan Produktivitas Pegawai.

Humaeroh, Susilo, H., \& Prasetya, A. (2015). Pengaruh Kompensasi terhadap Kepuasan Kerja Karyawan dan Dampaknya terhadap Motivasi Kerja ( Studi pada Karyawan PT Krakatau Steel ( Persero ) Tbk .). Jurnal Administrasi Bisnis (JAB), 27(2), 1-8. 
Italiani, F. A. (2018). Pengaruh Gaya Kepemimpinan Transformasional Dan Transaksional Terhadap Kinerja Pegawai Departemen SDM PT. SEMEN GRESIK (Persero) Tbk. BISMA (Bisnis dan Manajemen), 6(1), 11. https://doi.org/10.26740/bisma.v6n1.p11-18

Kadarisman, M. (2011). Pengertian dan Filosofi Manajemen Kompensasi. Manajemen Sumber Daya Manusia, 1-53.

Lumentut, M. D. ., \& Dotulong, L. O. . (2015). Pengaruh Motivasi, Disiplin, dan Lingkungan Kerja Terhadap Kepuasan Kerja Karyawan Pada PT. Bank SULUT Cabang Airmadidi. Jurnal EMBA, ISSN: 2303-1174, 3(1), 74-85.

Muguongo, M. M., Muguna, A. T., \& Muriithi, D. K. (2015). Effects of Compensation on Job Satisfaction Among Secondary School Teachers in Maara Sub - County of Tharaka Nithi County, Kenya. 3(6), 47-59. https://doi.org/10.11648/j.jhrm.20150306.11

Munir, R. I. S., Rahman, R. A., Malik, A. M. A., \& Ma'amor, H. (2012). Relationship between Transformational Leadership and Employees' Job Satisfaction among the Academic Staff. Procedia - Social and Behavioral Sciences, 65(ICIBSoS), 885-890. https://doi.org/10.1016/j.sbspro.2012.11.215

Nurhasanah, A. (2010). Kerja Karyawan Pada Bank Indonesia Cabang Samarinda. 6(1), 13491356.

Nursaid, N., Qomariah, N., Sanosra, A., Satoto, E. B., \& Utomo, A. W. (2020). Improvement of Job Satisfaction Based on Work Motivation, Work Environment, Competence and Compensation for Hospital Employees. Indonesian Journal Of Law and Economic Review, 1(1).

Prastyo, E., Hasiholan, L., Management, M. W.-J. of, \& 2016, U. (2016). Pengaruh Motivasi, Kepuasan, dan Lingkungan Kerja Terhadap Kinerja Karyawan Honorer Dinas Bina Marga Pengairan dan ESDM Kabupaten Jepara. Jurnal.Unpand.Ac.Id, 02(02).

Putra, I., \& Sariyathi, N. (2015). Pengaruh Gaya Kepemimpinan Transformasional, Lingkungan Kerja Dan Kompensasi Terhadap Kepuasan Kerja Karyawan Langgeng Laundry Di Kuta, Badung. E-Jurnal Manajemen Universitas Udayana, 4(5), 1345-1364.

Raziq, A., \& Maulabakhsh, R. (2015). Impact of Working Environment on Job Satisfaction. Procedia Economics and Finance, 23(October 2014), 717-725. https://doi.org/10.1016/s2212-5671(15)00524-9

Setiawan, F., \& Kartika Dewi, A. (2014). Pengaruh Kompensasi dan Lingkungan Kerja Terhadap Kinerja Karyawan Pada CV. Berkat Anugrah. E-Jurnal Manajemen Universitas Udayana, 3(5), 1471-1490.

Tambengi, Kevin F.S., Kojo, Christoffel, Rumokoy, F. S. (2016). Pengaruh Kompensasi, Beban Kerja, Dan Pengembangan Karir Terhadap Kepuasan Kerja Karyawan Pada Pt. Telekomunikasi Indonesia Tbk. Witel Sulut. Emba, 4(4), 1088-1097.

Taufiqqurrokhman, I. (2015). PENGARUH LINGKUNGAN KERJA DAN KOMPENSASI TERHADAP TURNOVER INTENTION PADA SWALAYAN BENTAR MOJOKERTO. Journal Ekobis Universitas Muhammadiyah Malang, 2(1), 1689-1699. https://doi.org/10.1017/CBO9781107415324.004

Widyani, A., \& Sugianingrat, I. (2015). Effect of multiple role conflict on job satisfaction with the mediation role of stress. International Journal of Economics, Commerce and Management, 3(5), 868-870.

Wuwungan, R., Taroreh, R., \& Uhing, Y. (2017). Pengaruh Lingkungan Kerja Dan Motivasi Kerja Terhadap Kepuasan Kerja Karyawan Cinemaxx Lippo Plaza Manado. Jurnal Riset Ekonomi, Manajemen, Bisnis dan Akuntansi, 5(2), 298-307. 